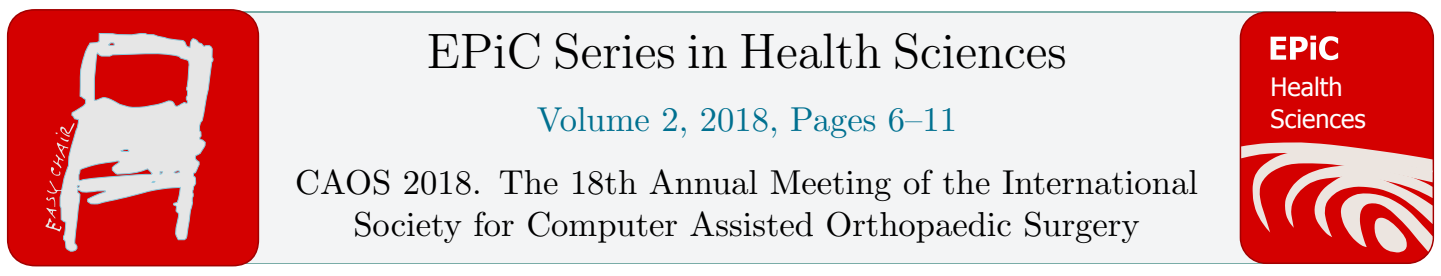

\title{
Detection and Grading of Knee Joint Cartilage Defect using Multi-Class Classification in Vibroarthrography
}

\author{
N. Befrui ${ }^{1}$, J. Elsner ${ }^{2}$, A. Flesser ${ }^{3}$, J. Huvanandana ${ }^{2}$, O. Jarrousse ${ }^{1,2}$, T. L. Le ${ }^{1}$, \\ M. Müller ${ }^{2}$, W. H. W. Schulze ${ }^{1,2,4}$, S. Taing ${ }^{2}$ and S. Weidert ${ }^{1}$ \\ ${ }^{1}$ Trauma Surgery Department, Ludwig-Maximilians-University Hospital, Munich, Germany \\ ${ }^{2}$ Munich Innovation Labs, Grünwald, Germany \\ ${ }^{3} \mathrm{CPE}$ GmbH, Willich, Germany \\ ${ }^{4}$ Evolunis UG, Knesebeck, Germany \\ Contact: Nima Befrui: nima.befrui@med.uni-muenchen.de
}

\begin{abstract}
Vibroarthrography describes the detection of joint pathologies by analysis of vibrations emitted during joint movement. In our study, 30 healthy volunteers and 39 patients with various degrees of chondromalacia or osteoarthritis were selected and accelerometers and piezoelectric sensors were placed on prominent bone structures of patients' knee joints (patella, lateral and medial tibial plateau) in order to measure the structure-borne noise during active extension and flexion of the joint. After semi-automatic signal segmentation had been applied to isolate flexion and extension cycles, features based on relative high-frequency components were generated. Using machine learning with a linear support vector machine, these signals were classified as healthy, exhibiting chondromalacia ${ }^{\circ} \mathrm{II}-\mathrm{IV}$ or osteoarthritis. $84 \%$ of healthy subjects were identified correctly, while the classification accuracy for individual stages of chondromalacia or osteoarthritis ranged from $11 \%\left(\mathrm{CM}{ }^{\circ} \mathrm{II}\right)$ to $50 \%$ (CM $\left.{ }^{\circ} \mathrm{III}\right)$. In order to make results easily interpretable without resorting to machine learning techniques, we propose a normalized score between 0 and 1 and show that this "v-score" for flexion and extension significantly correlates with the achieved multi-class classification. Vibroarthrography may qualify as potent screening tool for the detection and grading of joint cartilage defects and aid physicians in the choice and estimation of urgency of further diagnostic and therapeutic decisions.
\end{abstract}


Introduction

The progressive degeneration of articular cartilage known as chondromalacia and the pathological consequent reactions of bony structures in osteoarthrosis are among the leading causes of pain and disability in the middle-aged and elderly demographic and may lead to severe impairments in activities of daily life [1,2]. Early detection of such joint pathologies are of great importance to aid physicians with diagnostic and therapeutic decisions in early stages of cartilage degeneration. Current imaging modalities however either depict anatomical joint pathologies present only in later stages of osteoarthrosis (X-ray) or are prone to low inter observer reliability besides their high costs and low availability (MRI) [3]. Although previous VAG-studies demonstrated its capabilities in binary classification of joints as either healthy or pathological [4,5], there is limited data on the possibility of estimating the severity of cartilage damage. The grade of chondromalacia however is an essential information for any physician deciding upon further diagnostics and treatment options for his patient. The aim of our study was to evaluate Vibroarthrography (VAG) as a diagnostic tool for articular degeneration of the knee joint in respect to the correct identification of various grades of chondromalacia and osteoarthritis.

\section{$\underline{\text { Methods }}$}

The measurement system we established was comprised of 3 acoustic sensors mounted to the skin above selected prominent bony structures of the knee joint and dedicated to the recording of vibrations emitted from the joint during movement: one accelerometer on the patella, another accelerometer on the medial tibial plateau and a piezoelectric disk on the lateral tibial plateau. Joint angle was measured during motion by a potentiometer mounted to a knee orthosis. The VAG and knee angle signals were acquired simultaneously via a four-channel data acquisition unit at $16 \mathrm{kHz}$ sampling rate and 24 bits/sample. 39 patients presented with history of chondromalacia (' $\mathrm{CM}$ ') or osteoarthrosis ('OA') and evidence of articular cartilage degeneration of the knee in recent MRI; further 30 healthy volunteers participated in the study, resulting in a total case number of 59 'healthy' and 40 'pathological' joints analyzed. Severity of cartilage degeneration in the 'pathological' knees was as follows: $\mathrm{CM}^{\circ} \mathrm{II}: \mathrm{n}=3$; $\mathrm{CM}^{\circ} \mathrm{III}: \mathrm{n}=12$; $\mathrm{CM}^{\circ} \mathrm{IV}$ : $\mathrm{n}=16$; manifest osteoarthrosis: $\mathrm{n}=9$ )

Patients were asked to perform multiple full knee extensions and flexions from a sitting position with free swinging leg. Relative high-frequency features independent of signal gain were generated from the acquired VAG-signals from all sensors by calculation, normalization and averaging of estimated power spectra between $10 \mathrm{~Hz}$ and $8000 \mathrm{~Hz}$ of extension and flexion cycles respectively, resulting in a knee-specific feature vector [5]. With added normalization, frequency features proved to be simple and robust as they are insusceptible to influences on signal gain, such as fat tissue and variance in acoustic coupling. An assessment between the patient's body mass index ("BMI") and the frequency features revealed a correlation of only $23 \%$. A linear support vector machine (SVM), a 
machine learning algorithm, was then used to classify the feature vectors derived from the VAGsignals according to standardized grading of cartilage degeneration as healthy, chondromalacia ${ }^{\circ} \mathrm{II}-\mathrm{IV}$ or osteoarthrosis. For easy interpretation of results, we propose a normalized score between 0 and 1 for flexion and extension correlating with the achieved multi-class classification.

\begin{tabular}{|l|l|l|l|}
\hline \multicolumn{1}{|c|}{ Type } & \multicolumn{1}{|c|}{ Model } & \multicolumn{1}{c|}{ Localisation } & \multicolumn{1}{c|}{ Specification } \\
\hline $\begin{array}{l}\text { Acceleromete } \\
\text { r }\end{array}$ & $\begin{array}{l}\text { Model 352A24, PCB } \\
\text { Piezotronics, Inc., USA }\end{array}$ & $\begin{array}{l}\text { Patella, } \\
\text { medial tibial plateau }\end{array}$ & $\begin{array}{l}\text { Frequency range 1-8000 Hz }( \pm 5 \%) \\
\text { Sensitivity 10.09 mV/(m/s2) } \\
\text { Measurement range } 50 \mathrm{~m} / \mathrm{s} \\
\text { Resonant frequency 38 300 H } \\
\text { Constant current excitation 2-20 mA }\end{array}$ \\
\hline $\begin{array}{l}\text { Piezoelectric } \\
\text { disk }\end{array}$ & $\begin{array}{l}\text { Model EPZ-27MS44F, } \\
\text { Elektrotechnik Karl- } \\
\text { Heinz Mauz GmbH, } \\
\text { Germany }\end{array}$ & $\begin{array}{l}\text { Lateral tibial } \\
\text { plateau }\end{array}$ & $\begin{array}{l}\text { Resonant frequency } 4400 \mathrm{~Hz} \\
\text { Impedance 300 } \Omega\end{array}$ \\
\hline $\begin{array}{l}\text { Potentiomete } \\
\mathrm{r}\end{array}$ & $\begin{array}{l}\text { Model SW22E-10K, } \\
\text { ETI Systems, Inc., } \\
\text { USA }\end{array}$ & Orthosis & $\begin{array}{l}\text { Resistance } 10 \mathrm{k} \Omega \\
\text { Linearity } \pm 5 \% \\
\text { Tolerance } \pm 3 \% \\
\text { Mechanical angle 320 } \pm 5 \mathrm{degrees} .\end{array}$ \\
\hline $\begin{array}{l}\text { Data } \\
\text { acquisition }\end{array}$ & $\begin{array}{l}\text { Model DT9837, Data } \\
\text { Translation, Inc., USA }\end{array}$ & $/$ & $\begin{array}{l}\text { Four single-ended simultaneous channels } \\
\text { with 24- bit resolution, support for IEPE } \\
\text { inputs with current source 4 mAl, high- } \\
\text { pass filter 0.5 Hz }\end{array}$ \\
\hline
\end{tabular}

Table 1: Sensors and data acquisition unit used in the measurement protocol. 


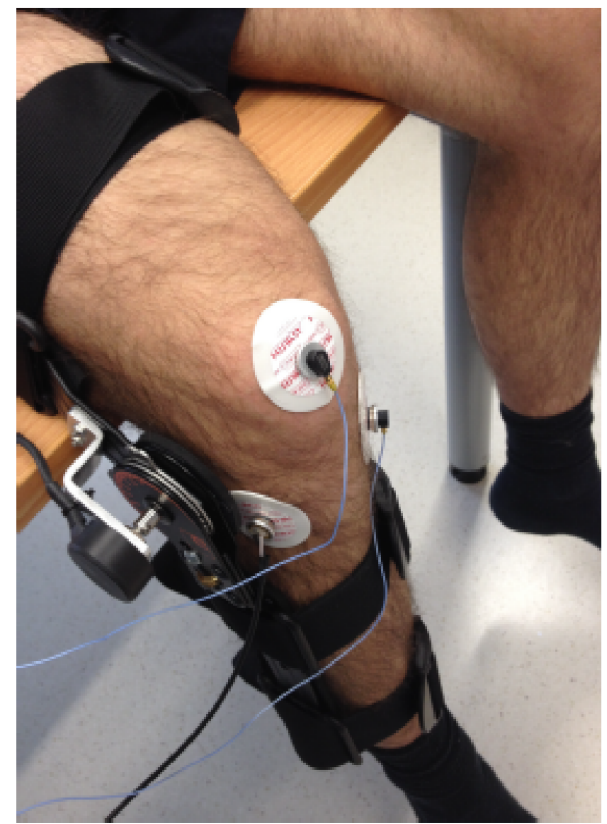

Fig. 1: Sensor measurement setup with accelerometers and the piezoelectric disk mounted to the patella, medial and lateral tibial plateau respectively via ECG-pads. The knee orthosis is fitted with a potentiometer constantly measuring the joint angle.

\section{$\underline{\text { Results }}$}

In the multi-class classification of the feature vectors using frequency features between $25 \mathrm{~Hz}$ and $8000 \mathrm{~Hz}$ and SVM, $84 \%$ of healthy individuals were identified correctly as such. Classification accuracy for individual degrees of chondromalacia ranged from $11 \%\left(\mathrm{CM}{ }^{\circ} \mathrm{II}\right)$ over $32 \%(\mathrm{OA})$ and $42 \%\left(\mathrm{CM}^{\circ} \mathrm{IV}\right)$ to $50 \%\left(\mathrm{CM}^{\circ} \mathrm{III}\right)$. 


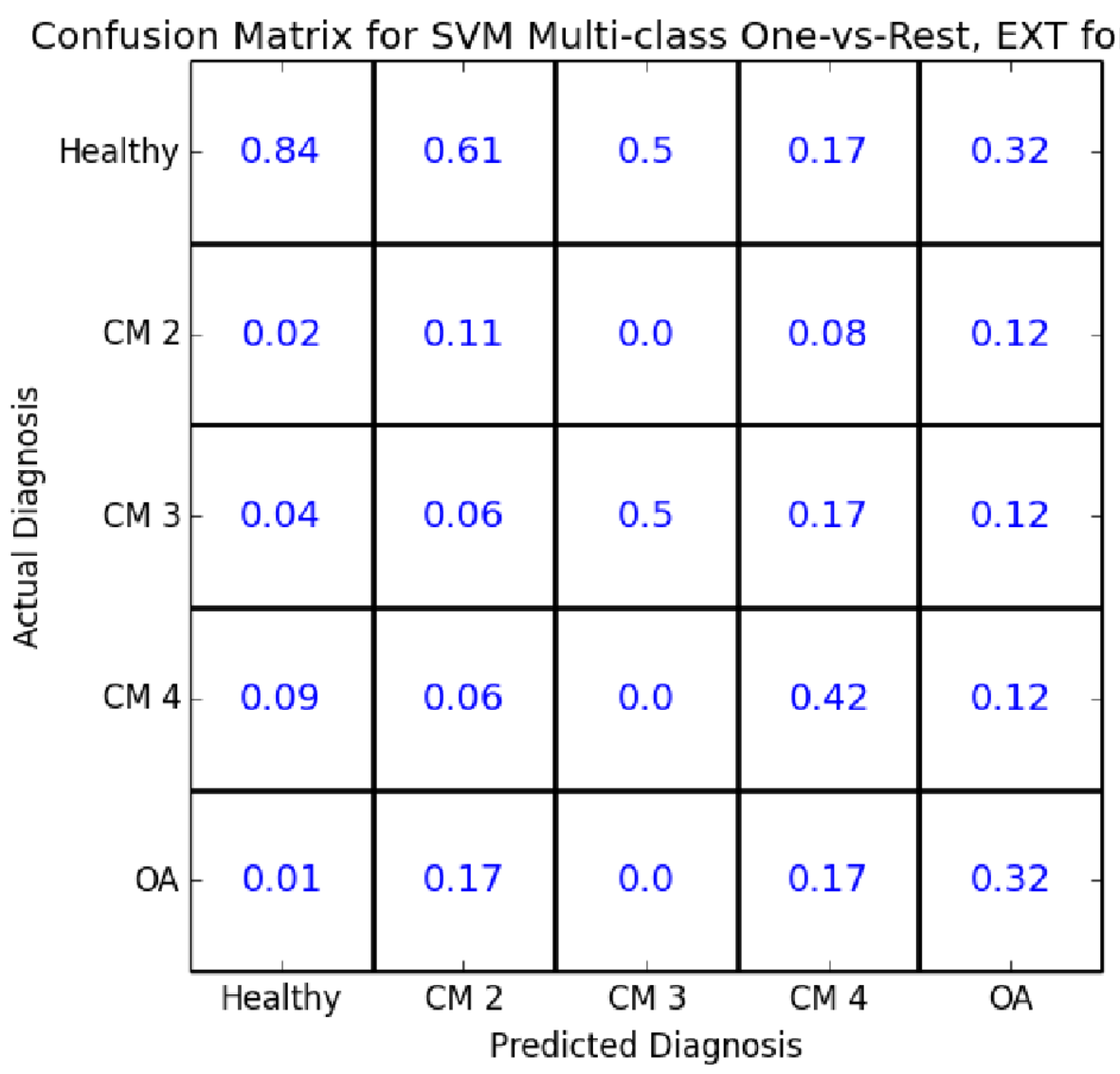

Fig. 2: Multi-class classification accuracy. Patients were classified as 'healthy', exhibiting chondromalacia ${ }^{\circ} \mathrm{II}-{ }^{\circ} \mathrm{IV}$ or osteoarthritis.

\section{$\underline{\text { Discussion }}$}

In our study we demonstrated the ability of Vibroarthrography to detect articular cartilage degeneration in the knee joint by analysis of vibration signals. While the test's specificity of $84 \%$ ranks among that of other established diagnostic tools in medicine $[6,7]$, the classification accuracy of individual chondromalacia grades is still limited. This could partly be explained by the low patient case number (e.g. 3 patients with $\mathrm{CM}{ }^{\circ} \mathrm{II}$ ), as well as moderate inter observer reliability in MRI imaging of knee joints, where an assigned CM-grade in an MRI-scan may not always reflect the actual anatomical severity of a cartilage defect [3]. By increasing our case number and transitioning to patients with diagnosis of cartilage defects in arthroscopy instead of MRI-scans, we aim to improve the classification accuracy of this promising technology. By using low-cost radiation-free vibration sensors, Vibroarthrography may qualify as potent screening tool for the detection and grading of joint 
cartilage defects and aid physicians in the choice and estimation of urgency of further diagnostic and therapeutic decisions.

\section{References}

1 Buckwalter, J. A., and H. J. Mankin. "Articular cartilage: degeneration and osteoarthritis, repair, regeneration, and transplantation." Instructional course lectures 47 (1998): 487-504.

2 Jackson, Douglas W., Timothy M. Simon, and Harold M. Aberman. "Symptomatic articular cartilage degeneration: the impact in the new millennium." Clinical Orthopaedics and Related Research ${ }^{\circledR} 391$ (2001): S14-S25.

3 Menashe, L. et al., "The diagnostic performance of MRI in osteoarthritis: a systematic review and meta-analysis" Osteoarthritis and Cartilage 20.1 (2012): 13-21

4 Moussavi, Zahra MK, et al. "Screening of vibroarthrographic signals via adaptive segmentation and linear prediction modeling." IEEE transactions on biomedical engineering 43.1 (1996): 15.

5 Befrui, N., Elsner, J., Flesser, A., Huvanandana, J., Jarrousse, O., Le, T. N., ... \& Weidert, S. Vibroarthrography for early detection of knee osteoarthritis using normalized frequency features. Medical \& biological engineering \& computing (2018) 1-16.

6 Pihlajamäki, Harri K., et al. "Reliability of clinical findings and magnetic resonance imaging for the diagnosis of chondromalacia patellae." JBJS 92.4 (2010): 927-934.

7 McCauley, Thomas R., et al. "Chondromalacia patellae: diagnosis with MR imaging." AJR. American journal of roentgenology 158.1 (1992): 101-105. 